\title{
Fire spread prediction using a lagged weather forecast ensemble
}

\author{
$\underline{\text { S.A. Louis }}^{\mathrm{a}}$ and S. Matthews ${ }^{\mathrm{b}}$ \\ ${ }^{a}$ NSW Severe Weather Section, Bureau of Meteorology, Sydney, NSW 2000 \\ ${ }^{b}$ NSW Rural Fire Service, Lidcombe, NSW 2141 \\ Email: s.louis@bom.gov.au
}

\begin{abstract}
From October to early December 2014 the Bureau of Meteorology conducted a pilot trial of a Rapid Update Cycle (RUC) numerical weather model. The model was run at a horizontal resolution of approximately $1.5 \mathrm{~km}$, with hourly updates to the forecast, and was nested within the operational ACCESS suite of weather models. At this resolution, convection can be resolved without parameterization and the influence of topography on near surface conditions should be better captured. As part of this trial the model data was made available to the NSW Rural Fire Service in order to gauge how useful it would be in an operational setting.
\end{abstract}

We present a set of three case studies of wildfires that occurred during the RUC trial period. In each case a short overview of the fire is presented, and the broad synoptic scale weather pattern outlined. The 0000UTC RUC model run and the morning official Australian Digital Forecast Database (ADFD) nearest grid cells were compared with observations at a nearby Automatic Weather Station (AWS) location as a check on the broad scale performance of the model. The gridded weather at the fire ignition point was then compared with the gridded weather at the AWS site to assess any local variation in expected conditions, e.g. wind change timing. The RUC guidance and ADFD guidance were then used as input to the Phoenix fire spread model, with an examination of the relative performance of each model in predicting the resulting fire spread. For each case, a proof of concept lagged ensemble 'probability burnt' prediction map was produced using five consecutive (unweighted) RUC forecasts. RUC model runs were initiated hourly on the morning of each case study from 0700 local time (2000UTC on the previous day). All times are given below as UTC.

One issue that we encountered with attempting to construct a lagged ensemble type fire spread product was that the intermediate RUC model runs (i.e. those falling between the major six hourly updates) had quite short forecast time domains, and an overlapping period of a few hours only was available. This was considered sufficient to assess the initial phase of fire spread, however, and comparisons with the actual burn extent generally become more difficult on longer time scales as active suppression becomes more of a factor.

The selection of cases to examine was based on a combination of an interesting weather situation, a sufficiently large fire run, and the availability of aircraft linescan data at appropriate times to verify the actual fire spread. We also wanted to ensure that we examined at least one case in predominately grass fuels and one case in predominately forest fuels. None of the cases selected occurred under extreme weather conditions, as little extreme weather occurred during the RUC trial period, and uncertainty around the applicability of the fire behaviour models that underpin Phoenix in extreme conditions would make comparisons with the actual fire spread maps less certain.

We also present a short discussion on the sensitivity of the Phoenix model to fuel state, ignition pattern and the weather forecast, and consider the relative magnitudes of these sensitivities with reference to one of the case study fires, showing that sensitivity to the weather forecasts is comparable to the other inputs.

Keywords: Ensemble modelling, fire behaviour, Phoenix 


\section{INTRODUCTION}

Prediction and modelling of the behaviour and rate of spread of wildfires is of increasing importance to Australian emergency service organisations, with operational fire spread predictions being used to guide decisions around fire suppression activities and community advice and warnings. Models for fire behaviour and growth that have been used in the Australian environment (Cruz 2015 et al.) are sensitive to many factors, including fuel state and topography, but one key factor that cuts across all fire spread models is the need for accurate predictions of weather elements including the air temperature, humidity and wind speed and direction.

The PHOENIX fire spread model (Tolhurst et al. 2008) has been used to support operations in the New South Wales Rural Fire Service (NSW RFS) since 2012. PHOENIX uses two basic fire behaviour models, the CSIRO southern grassland fire spread model (Cheney et al. 1998) and the McArthur Mk5 forest fire behaviour model (McArthur 1967, Noble et al. 1980), with some modifications to account for some dynamic interactions between the fire and environment, to numerically model the change in the perimeter of a given fire. The NSW RFS runs the Phoenix model on a $180 \mathrm{~m}$ spatial grid with fire perimeters propagated as vectors. Weather input is taken from the official Bureau of Meteorology Australian Digital Forecast Database (ADFD), which provides hourly forecasts of weather parameters on a $6 \mathrm{~km}$ grid (Australian Bureau of Meteorology 2015). The ADFD grids are produced from numerical weather model guidance that has been manually edited by forecasters based on their knowledge and experience.

From October to early December 2014 the Bureau of Meteorology conducted a pilot trial of a high resolution, Rapid Update Cycle (RUC) numerical weather model (Seed et al. 2015, Ebert et al. 2015). The model was run at a horizontal resolution of approximately $1.5 \mathrm{~km}$, with hourly updates to the forecast. At this resolution some convective cloud processes can be resolved without parameterization, and the influence of topography on near surface conditions should be better captured. As part of this trial the model data was made available to the NSW RFS in order to gauge how useful it would be in an operational setting.

To assess whether the RUC forecast data could improve operational fire spread predictions using PHOENIX we prepared three cases studies based on actual fires during the trial period. The two main aims were to assess whether the higher resolution of the forecast could provide a better representation of the interaction between wind and topography than the ADFD, and whether the rapid update cycle nature of the forecasts could be leveraged to create a basic lagged ensemble forecast of the fire spread. In this case, consecutive hourly runs of the RUC model were used as the ensemble members, with resulting Phoenix predictions overlaid to infer a 'probability burnt' from the fraction of predictions showing burned area. No weighting of the lagged ensemble members was attempted as no clear way to objectively identify weights from past performance was identified. CASE 1 - Kurri Kurri Fire, 2/11/2014

A fire ignited just to the south of the town of Kurri Kurri (32.84S 151.47E) with the first Situation Report (SitRep) received at 2033UTC. Fire spread was initially towards the ENE, but then shifted towards the NW following a southerly wind change reported in a SitRep at 0220UTC. Suppression was used, including aerial attack. An aircraft linescan was taken at 0249UTC, just after the reported onset of the southerly wind change. Due to the proximity to the southern edge of the Kurri Kurri urban interface the fire was classed as a Watch and Act alert level for a period during the day.

\subsection{Synoptic Situation}

A cold front had moved across the previous day, leaving a fresh and very dry W to SW airstream across the area. An embedded secondary trough in the SW air stream triggered a wind shift from WSW to S as it crossed the area during the day. The morning sounding at Williamtown shows that the post frontal boundary layer was around $1500 \mathrm{~m}$ deep, with a (very dry) mixing ratio of less than $2 \mathrm{~g} / \mathrm{kg}$.

\subsection{Weather - Comparison between forecasts and observations}

The wind recorded at Cessnock AWS (located around $13 \mathrm{~km}$ to the NW of the fire ground) in the morning and early afternoon was generally from the W/WSW at around 3 to $4 \mathrm{~m} / \mathrm{s}$, apart from a brief period where the wind turned more lighter NW'ly at around 1900UTC. The ADFD forecast captured the wind speed reasonably well during this period but predicted a more SW wind direction.

Between 0230UTC and 0600UTC the wind direction at the AWS became very erratic, varying rapidly in directions ranging from $170^{\circ}$ to $360^{\circ}$, with the speed remaining at around $3 \mathrm{~m} / \mathrm{s}$. The initial change to SSE corresponded with a SitRep from the fire reporting a southerly wind shift and erratic fire behaviour. Neither the ADFD or the RUC model captured these rapid wind direction shifts particularly well, with both showing 
a gradual backing in wind from WSW to SSE, with the backing occurring about two hours earlier in the RUC model relative to the ADFD.

At 0630UTC the wind at the AWS suddenly shifted SE, with an increase in wind speed to almost $7 \mathrm{~m} / \mathrm{s}$. The wind remained SE'ly for a few hours, although the speed gradually decreased back down to $2 \mathrm{~m} / \mathrm{s}$, then switched back to SW'ly at 1030UTC remaining calm or light from this direction for the remainder of the night. The RUC captured the strength of the SE wind better than the ADFD, with a peak wind speed of 6.6 $\mathrm{m} / \mathrm{s}$ compared to $5.2 \mathrm{~m} / \mathrm{s}$, although the RUC appears to have introduced the SE'ly wind surge an hour too early. The RUC also did a better job of capturing the strength and direction of the light overnight wind, likely because it was a locally topographically forced drainage flow underneath the surface inversion.

The temperature and humidity during the day were generally well forecast by the ADFD and the RUC, however the humidity recovery began too soon in the RUC forecast as a result of the SE'ly arriving too early. The ADFD captured the overnight minimum temperature, and also as a result the maximum overnight humidity, better than the RUC.

\subsection{Phoenix Spread Predictions}

Mapped fire perimeters were available at 0152UTC and 0751UTC, so Phoenix was run using the 0152UTC perimeter as the initial fire edge to predict the fire spread between 0200UTC and 0700UTC. Figure 1a shows that the five RUC model runs and the ADFD forecast produced qualitatively similar predicted fire spreads, with an initial run to the ENE as a head fire, before the wind change caused the left flank of the fire to run to the NNW. The ADFD captured the extent of the head fire run slightly better than the RUC models, but all models except for the 2000UTC RUC run took the flank a similar distance to the NNW, and much further than the actual spread by 0751UTC. In this case suppression efforts on the northern flank likely had a large effect on the over-prediction relative to the actual area burnt. All of the actual burnt area was covered by at least 4 of the 5 RUC lagged ensemble members (Figure 1b) apart from a small section at the eastern end of the head fire run.
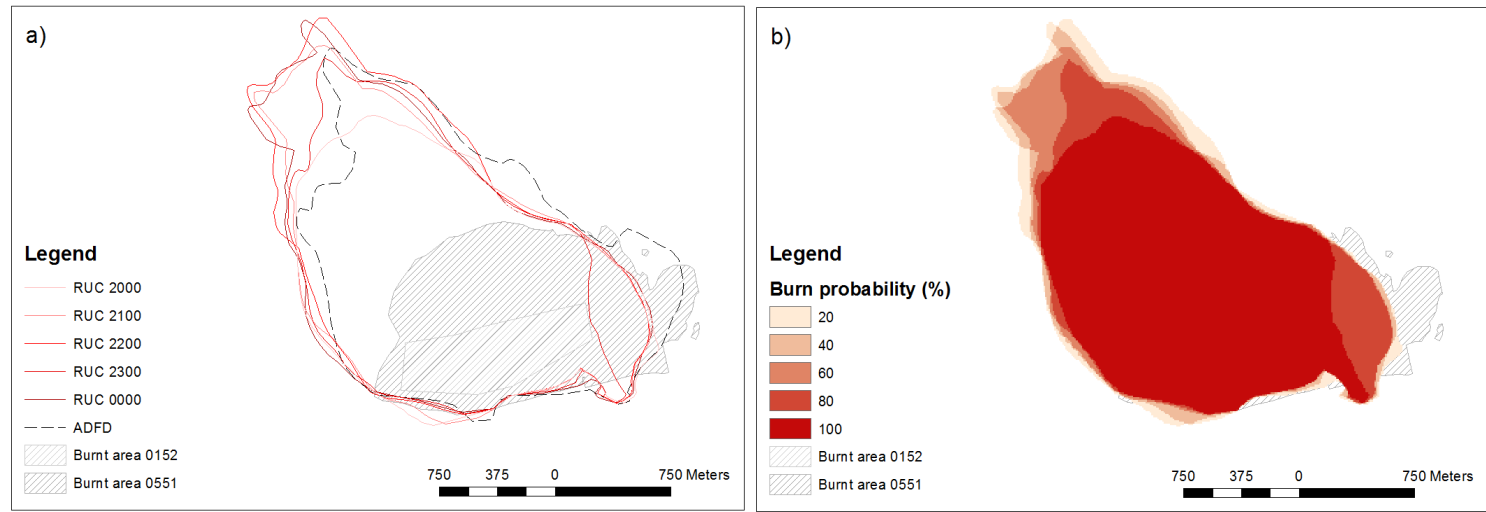

Figure 1. a) Kurri Kurri road fire Phoenix spread predictions. Polygon with widely spaced diagonals shows the initial fire perimeter at 0152UTC, polygon with close diagonal shading shows the actual burnt area at 0751UTC. The red polygons show the Phoenix predictions for burnt area at 0700UTC using the 2000UTC to 0000UTC RUC model runs, the black dashed polygon shows the Phoenix prediction for burnt area using the morning ADFD forecast. b) Lagged ensemble 'probability burnt' prediction map for Kurri Kurri fire.

\section{CASE 2 - HUME HIGHWAY COOLAC FIRE, 14/11/2014}

A fire ignited at around 0349UTC on the $14^{\text {th }}$ of November (34.91S 148.17E). The fire spread southeastwards through grassland from a bend in the Hume Highway, with the final extent of south-easterly spread achieved by around 0541UTC. A line scan showing the extent of the fire spread was taken at 0842UTC. Suppression including aerial attack was used on the fire.

\subsection{Synoptic Situation}

A cold front was moving past well to the south of NSW, with an associated low pressure trough extending back across southwest NSW. During the $14^{\text {th }}$ ridging from a high pressure centre to the southwest of Perth pushed the trough from the southwest of NSW into central NSW. Ahead of the trough a hot and dry prefrontal NW regime prevailed, while behind the trough a somewhat cooler S/SW air stream became established, although the temperature gradient across the trough was not particularly sharp. The morning 
sounding from Wagga Wagga showed a mixed layer with potential temperature of around $36{ }^{\circ} \mathrm{C}$ and a mixing ratio of $5 \mathrm{~g} / \mathrm{kg}$. The observed maximum temperature of almost $40{ }^{\circ} \mathrm{C}$ implies that the boundary layer reached a depth of over $4000 \mathrm{~m}$ with a mixing ratio of between 3 and $5 \mathrm{~g} / \mathrm{kg}$.

\subsection{Weather - Comparison between forecasts and observations}

The nearest AWS, at Wagga Wagga airport, is located approximately $71 \mathrm{~km}$ at a bearing of 240 degrees from the fire location.

The RUC and ADFD forecasts for the grid cell containing Wagga Wagga AWS both captured the pre trough temperature and humidity very well, with forecast maximum temperatures of $39.6{ }^{\circ} \mathrm{C}$ and $40.3{ }^{\circ} \mathrm{C}$ compared to the observed maximum of $39.6{ }^{\circ} \mathrm{C}$, and forecast minimum humidity of $8 \%$ and $7.3 \%$ compared to the observed minimum of $5 \%$. Both forecasts showed a weak humidity recovery overnight following the passage of the trough, but neither made the humidity recovery weak enough.

The fire appears to have started when the fire danger peaked at around 0400UTC. The observations from Wagga Wagga AWS show a rapid change from WNW to SW commencing from 0439UTC and then SSW by 0530UTC. The ADFD forecast also showed a single wind shift from W to SSW, but occurring a bit later, between 0600UTC and 0700UTC, while the RUC forecast appears to show a slightly more complicated structure, with a shift between WNW and SW occurring between 0300UTC and 0400UTC, then a second shift from SW to S occurring between 0600UTC and 0700UTC. The ADFD wind speed forecasts were consistently 2 to $3 \mathrm{~m} / \mathrm{s}$ higher than observed during the day, while the RUC wind speeds were 1 to $2 \mathrm{~m} / \mathrm{s}$ lower than observed.

For the grid cell containing the fire ground, the forecast wind speeds were also quite different, with the RUC being around $4 \mathrm{~m} / \mathrm{s}$ slower than the forecast from the ADFD. The wind directions were fairly similar at the time of the initial fire run, and the earlier two-stage wind shift was also present here in the RUC compared to a later, more sudden wind shift in the ADFD. The initial wind shift to SW was at 0600UTC in the RUC, which is within the window for which the Phoenix model was run, while the wind shift in the ADFD forecast was not until 0800UTC.

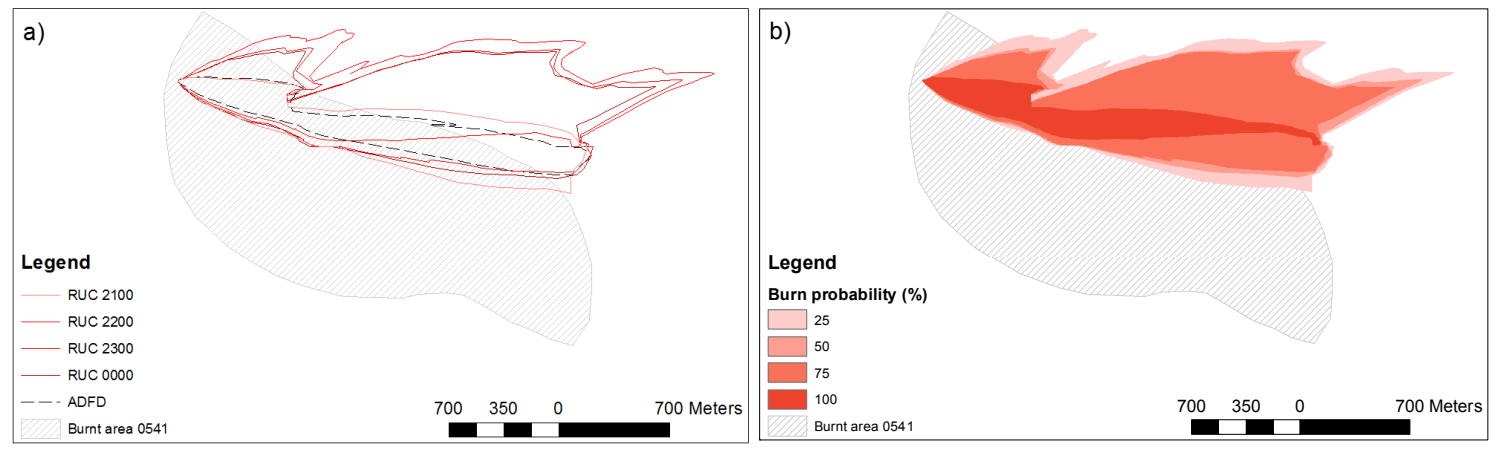

Figure 2. a) Hume Highway Coolac fire spread predictions. Polygon with close diagonal shading shows the actual burnt area at 0541UTC. The red polygons show the Phoenix predictions for burnt area at 0600UTC using the 2000UTC to 0000UTC RUC model runs, the black dashed polygon shows the Phoenix prediction for burnt area using the morning ADFD forecast. b) Lagged ensemble 'probability burnt' prediction map for Hume Highway Coolac fire.

\subsection{Phoenix Spread Predictions}

Figure 2a shows the burnt area at 0541UTC, as well as predictions of the fire spread from 0400UTC to 0600UTC using the ADFD and a series of RUC forecasts. The direction of the head fire run to the ESE was consistent across all of the weather scenarios, but the actual fire had a more SE head fire run with a difference of around $20^{\circ}$. The wind may have been locally funnelled in a more N/NW direction by the Mooney Mooney range, which runs north-south directly to the east of the fire location.

The $80-100 \%$ probability burnt area (Figure $2 \mathrm{~b}$ ) showed that all RUC model runs captured the initial E-SE head fire run under the W/NW pre-change wind regime, and a broad $60 \%$ burnt area extending to the northeast, indicating that 3 of the 5 RUC model runs predicted a SW change to reach the fire ground within the forecast period. It is clear that the 2000UTC and 2100UTC RUC model runs (and the ADFD forecast) did not have the SW change reaching the fire ground by 0600UTC with just a head fire run resulting, while the 2200UTC, 2300UTC and 0000UTC RUC model runs did bring the SW change through, resulting in the northern flank becoming the head fire. In this case the later RUC model runs produce a better match to the 
overall fire size and shape at 0741UTC than the earlier RUC runs or the ADFD, so the RUC has added significant value.

\section{CASE 3 - GREENS ROAD, WARRIMOO, 14/11/2014}

A fire started in rugged terrain to the west of Warrimoo at around 0240UTC (33.73S 150.59E) taking a run to the east and then southeast in hot conditions in the early afternoon, with intermittent crowning and average flame heights of 5 to $6 \mathrm{~m}$ reported. Fire activity eased in the late afternoon and evening, before increasing again with a southerly change that was reported at the fire ground in a Sit Rep at 1023UTC. Flame heights up to 6 to $7 \mathrm{~m}$ were reported at 1032UTC. A linescan showing the extent of the fire spread and active fire areas was taken at $1154 \mathrm{UTC}$.

\subsection{Synoptic Situation}

The synoptic situation was initially the same as for the Coolac fire case, with a hot air mass and NW gradient wind ahead of the trough. A boundary layer convergence line between more humid N/NE sea breeze air and hot deep mixed NW winds was tracked using weather radar, and instability associated with this boundary may have played a role in the initial period of erratic fire behaviour. By 1200UTC a bubble high had formed off the NSW coast, and an associated strong and gusty southerly change had extended along southern and central parts of the NSW coast in the wake of a low pressure trough. The morning aerological diagram from Sydney Airport showed that a strong overnight inversion had developed at $7 \mathrm{am}$ local time, with a temperature in the mid 30 's ${ }^{\circ} \mathrm{C}$ needed before deep turbulent mixing was likely.

\subsection{Weather - Comparison between forecast and observation}

The nearest AWS was at Penrith Lakes, around $8 \mathrm{~km}$ to the east of, and $250 \mathrm{~m}$ lower than, the fire ground. The winds reported at the Penrith AWS in the morning were light and variable under the influence of the surface inversion. The inversion was quite strong, so mixing into the westerlies aloft did not commence until the surface temperature reached the high $30^{\prime} \mathrm{s}{ }^{\circ} \mathrm{C}$ at around 0300UTC. The wind direction then shifted to the $\mathrm{N} / \mathrm{NW}$, with an increase in wind speed to 3 to $5 \mathrm{~m} / \mathrm{s}$ for the middle to late part of the afternoon as a deep warm well-mixed layer prevailed over Penrith. The wind speed dropped back below $3 \mathrm{~m} / \mathrm{s}$ from around 0730UTC as the surface temperature began to drop and another inversion began to form. The southerly change arrived at the AWS at around 1000UTC, with the wind speed in the southerly increasing to $6 \mathrm{~m} / \mathrm{s}$ at 1100UTC before easing back again. The ADFD forecast did not capture the variability in wind direction in the morning, and increased the wind speed to 4 to $5 \mathrm{~m} / \mathrm{s}$ well before the surface inversion broke. It did capture the wind direction well once the deep mixed layer had developed, as well as the easing in wind speed in the late afternoon. The RUC completely mis-forecast the wind direction in the afternoon, placing the sea breeze boundary line on the wrong side of Penrith, with wind speeds during the afternoon generally too low. Both the ADFD and RUC did a good job of capturing the timing and strength of the southerly change, although the RUC did a slightly better job of picking the wind speeds as the southerly weakened overnight. The ADFD did a good job of forecasting the temperature and relative humidity at Penrith overall, although it did decrease the humidity too quickly in the morning. As the RUC incorrectly placed the sea breeze boundary to the west of Penrith during the afternoon the temperature was not quite high enough, and the humidity not low enough in the afternoon, and the humidity also jumped back up into the 65 to $75 \%$ range hours too early.

The RUC forecast for the grid cell nearest the fire ground also predicted that the sea breeze boundary would remain to the west during the afternoon, with correspondingly slightly lower temperature and significantly higher humidity. The RUC prediction for the fire ground did show a slightly more complex situation just prior to the southerly change than its prediction for the Penrith AWS site, with a light NW'ly starting to develop and advect in significantly drier air.

Fire ground observations of wind direction and temperature seem to confirm that the ADFD forecast was correctly predicting that the fire ground would be to the west of the sea breeze boundary during the afternoon, however the relative humidity observations were closer to those forecast by the RUC. The relative humidity recovery appears to have begun a little later than forecast by the RUC, but earlier than in the ADFD, and the relative humidity observed immediately following the change appeared to be close to both forecast models.

\subsection{Phoenix Spread Predictions}

Fire extent polygons were available at 0340UTC and 0511UTC, so Phoenix predictions covering the period 0330UTC to 0500UTC were produced using the ADFD forecast and the five RUC forecasts initialized from 
2000UTC to 0000UTC (Figure 3a). In this case the RUC model runs have failed to predict the broad scale weather regime, and so Phoenix appears to have produced a forecast for topographically driven fire growth instead of the more elliptically shaped wind driven southeast moving head fire that actually occurred. Figure $3 \mathrm{~b}$ shows that there was sufficient variation between the RUC model runs in this case to produce a potentially useful probability burnt prediction map, however this case highlights the danger of this approach in a situation when the broad scale weather situation is not being well captured by the model.

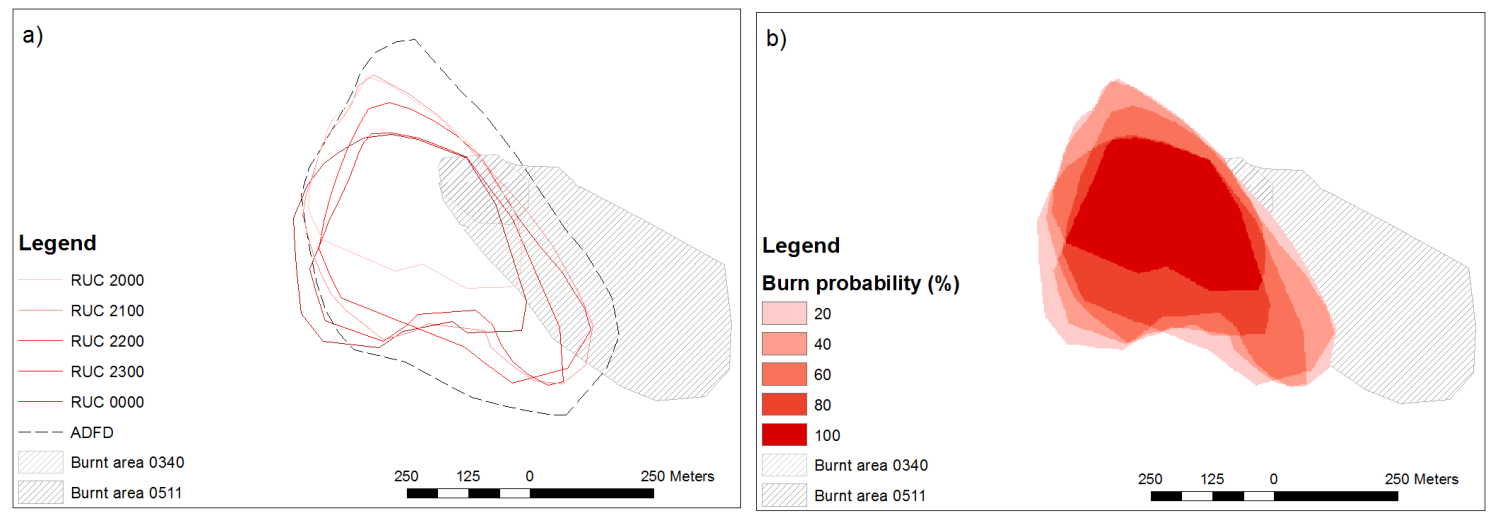

Figure 3. a) Greens Road, Warrimoo fire spread predictions. Polygon with widely spaced diagonals shows the initial fire perimeter at 0340UTC, polygon with close diagonal shading shows the actual burnt area at 0511UTC. The red polygons show the Phoenix predictions for burnt area at 0500UTC using the 2000UTC to 0000UTC RUC model runs, the black dashed polygon shows the Phoenix prediction for burnt area using the morning ADFD forecast. b) Lagged ensemble 'probability burnt' prediction map for the Greens Road, Warrimoo fire.

\section{SENSITIVITY OF THE FIRE SPREAD MODEL}

\subsection{Grass fuel load}

For Phoenix modelling NSW RFS uses a static fuel type map which assigns 30x30m grid cells to one of 51 fuel types. Fire history is used to calculate fuel loads from exponential decay curves. For grass types the fast decay rate means that fuels not burnt in the current season are near the long-term maximum fuel load. For the Coolac fire the majority of the fire area was assigned to a crop fuel type with load of $1.5 \mathrm{t} \mathrm{ha}^{-1}$. NSW RFS also has a grass land fuel load layer based on field observations. The Coolac fire was in the Riverina Highlands fuel reporting area and had a fuel load of $4.5 \mathrm{t} \mathrm{ha}^{-1}$ at the time of the fire. Phoenix was run from a point ignition with the 00UTC RUC grid with 1.5 and $4.5 \mathrm{t} \mathrm{ha}^{-1}$ fuel loads (Figure 4a). Tripling the fuel load approximately tripled the rate of spread and lead to a fire with 12 times the area.

\subsection{Initial fire perimeter}

Phoenix is known to be sensitive to the location, size and shape of the initial fire perimeter. To examine sensitivity to initial perimeter Phoenix was run using the 0000UTC RUC grid as: point ignition, $4 \mathrm{x} 4 \mathrm{~m}$ square, and $100 \times 100 \mathrm{~m}$ square. The point and $4 \mathrm{~m}$ ignitions resulted in similar area fires but the $100 \mathrm{~m}$ ignition area produced a significantly larger fire (Figure $4 \mathrm{~b}$ ).

\section{DISCUSSION AND CONCLUSIONS}

Overall the case studies showed that the RUC model data can provide improved weather input in some situations and assist with producing improved Phoenix fire spread predictions. The case study looking at the sensitivity of Phoenix to various inputs suggest that the sensitivity to the forecast weather provided is similar to the sensitivity of Phoenix to other inputs such as fuel state and ignition geometry, suggesting that there is value in pursuing improved weather inputs for the model. The lagged ensemble products produced using the RUC weather model data provide a proof of concept for more probabilistic fire spread forecasts in the future.

Some difficulties were encountered that made producing quantitative assessments of the Phoenix model performance too difficult. The actual spread rates and behaviour of the fire are difficult to determine exactly, and need to be pieced together from a combination of line scan data, situation reports and aerial photography. In addition to this, active suppression of the fires makes it difficult to assess the fire spread model performance beyond the initial first few hours of spread in many cases. 

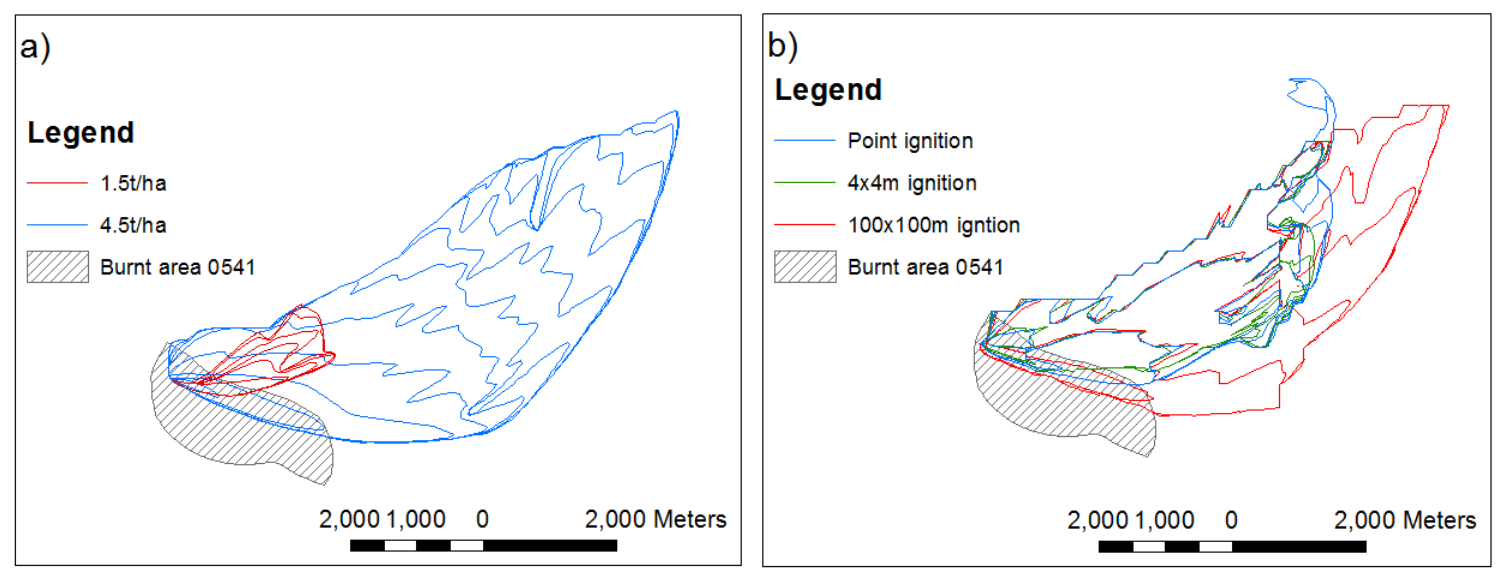

Figure 4. a) Fire spread isochrones for RUC weather forecast initialized at 0000UTC using Phoenix v3.9 with 1.5 and 4.5 t/ha grass fuel load. b) Fire spread isochrones for RUC weather forecast initialized at 0000UTC using Phoenix v4.0.07 with three different ignition sizes.

Another issue was that limited overlap between the RUC model time domains meant that no more than five hourly runs could be combined to create the lagged ensemble type products. There also appeared to be underdispersion between RUC model runs, with much of the variance in the lagged ensemble products coming from the 6-hourly boundary condition updates to the RUC model.

Future work is predicated on future trials or operationalisation of the RUC model, but could involve looking at whether appropriate weightings could be applied to the RUC lagged ensemble members, investigating ways to make more quantitative assessment of the fire spread performance, and more direct comparisons between the RUC model driven spread predictions and fire spread predictions using the operational ACCESS numerical weather models to give a cleaner idea of the improvement gain from higher resolution. Future opportunities could also exist to look at using a true ensemble weather forecast model for producing fire spread predictions.

\section{REFERENCES}

Australian Bureau of Meteorology (2015). Australian Digital Forecast Database User Guide. Available from http://reg.bom.gov.au/catalogue/adfdUserGuide.pdf. [28 July 2015].

Cheney, N.P., Gould, J.S., \& Catchpole, W.R. (1998). Prediction of fire spread in grasslands. International Journal of Wildland Fire 8, 1-15.

Cruz, M.G., Gould, J.S., Alexander, M.E., Sullivan, A.L., McCaw, W.L., Matthews, S. (2015). A Guide to Rate of Fire Spread Models for Australian Vegetation. CSIRO Land and Water Flagship, Canberra, ACT, and AFAC, Melbourne, Vic, 123pp.

Chong, D., Tolhurst, K., \& Duff, T. (2012). PHOENIX Rapidfire 4.0's Convection and Ember Dispersal Model. Bushfire CRC.

Ebert, E., Cope, M., Wain, A., Smith, D., \& Lee, S., (2015) The Air Quality Sub-Project of the Sydney Forecast Demonstration Project (FDP). Preliminary project report, April 2015, $21 \mathrm{pp}$.

McArthur, A.G. (1967). Fire behaviour in eucalypt forests. Leaflet 107. Commonwealth of Australia Forestry and Timber Bureau.

Noble, I.R., Bary, G.A.V., Gill, A.M. (1980). McArthur's fire-danger meters expressed as equations. Australian Journal of Ecology 5, 201-203.

Seed, A., Bell, A., Steinle, P., Richter, H., Foley, M. (2015), Sydney Forecast Demonstration Report (in preparation), Australian Bureau of Meteorology

Tolhurst, K, Shields, B, Chong, D (2008). Phoenix: development and application of a bushfire risk management tool. Australian Journal of Emergency Management 23, 47-54. 